\title{
Using Theory of Planned Behaviour to Understand Students' Perception in Gap Year
}

\author{
Yip Foon Yee
}

\begin{abstract}
The high competitive work environment required student not only learn the knowledge and current skill through classroom, they also need opportunity to practice their learned knowledge from classroom. Therefore, gap year program is the bridge to increase and explore students' experience. The current study use Ajzen's theory of planned behavior (TPB) to examine the intentions of diploma students toward taking gap year and also investigate the current students' perception on taking a gap year. Questionnaire was used to investigate the purpose of the study. Multiple regression analyses supported the predictive validity of the theory in this context, with the three predictor variables (attitude, subjective norm and perceived behavioural control) accounting for $73 \%$ of the variance in students, intentions to take gap year. Our results indicated that perceived behavioral control and subjective norm were significant related with intention to taking gap year but the attitude was not significant related with intention to taking gap year. Based on result, we found most of the student in Malaysia are not aware the gap year program in Malaysia. If they are given opportunity, most of them agreed to join the gap year program. Limitations of present study are discussed. Implications of the findings and areas for future research are also presented.
\end{abstract}

Keywords : Gap Year, Generation Z, Theory of Planned Behavior,

\section{INTRODUCTION}

With globalization has come the need for organizations throughout the world to deal with the challenges of drastic change in technology and market liberalization. Youth plays important role in to compete effectively in global. High skilled youth might lead higher productivity of the organization. However, recently you can found out the unemployment rate among youth is increasing. The Department of Statistics Malaysia found that the unemployment persons in Malaysia had increased from 450,300 in 2015 to 521,400 in 2019. [1][2]

One of the main reason that lead to high unemployment rate is low quality of graduates. Aziz 3 stated that employers in Malaysia think the universities do not provide enough opportunity for students to develop abilities critical to the labour market. Based on findings, OUT of 15 employability skills (see infographics) that were examined, it is found that employers expressed dissatisfaction with 12 of them in

Revised Manuscript Received on October15, 2019.

* Correspondence Author

Yip Foon Yee*, Faculty of Business, Communications and Law, INTI International University, Persiaran Perdana BBN, Putra Nilai, 71800 Nilai, Negeri Sembilan, Malaysia. Email: foonyee.yip@newinti.edu.my

This research was supported by Seed Grant, INTI International University, Nilai graduate hires' capabilities [3]. In order to solve low quality of graduate, Ex-higher Education Ministry introduced the Gap Year programme to allow undergraduates from Malaysian Public Universities to take a year, or two semesters, off from their formal education to engage in volunteer activities.

The 'gap year' is defined as a time between the end of school and the beginning of further studies in which young people engage in a variety of activities, including paid or voluntary work 4 . A gap year is important for student because it allows them to gain experience and build connections, do volunteer work, enlist in a public service department, and or do something they are really passionate about. Nowadays, the current generation of student more likely to be digitally-based, fast-paced and require greater depth and breadth of knowledge. Taking a gap-year during their tertiary schooling might prepare them adequately for labor market. Previous studies have indicated that gap years has positive effect on academic performance, language development, personal growth and career attainment [4][5][6][7][8]. Besides that, there are numbers of top university encourage their student have gap year. However, there are limited research in Malaysia on students' perception of a gap year especially in Malaysia. Thus, this study is to investigate whether student of Malaysia intent to take a gap-year before or during their schooling in university .

Previous studies have used the TPB to predict behavioral intentions in relation to various events, such as presenting at class lectures [9] and attaining certain academic achievements. However, limited number of studies have used theory of planned behavior to explain and predict student intent to take a gap-year. There are three predictor variables of the theory of planned behaviour are themselves considered to be underpinned by individuals' beliefs about the behaviour. Attitude is governed by behavioural beliefs (beliefs and evaluations regarding the outcomes of the behaviour), subjective norm by normative beliefs (beliefs about the expectations of others and the motivation to comply with these) and perceived behavioural control by control beliefs (factors that might facilitate or limit the behaviour and the importance of these factors). The present study will use theory of Planned Behavior to investigate the factor that lead to intention of taking a gap year. 


\section{LITERATURE REVIEW}

\section{A. Gap year}

According to O'Shea [5], Gap year developed from British experiences. Gap year first become common in 1960s, during that time British young man love to join a tour called European Grand Tour. They stated that this tour can be served as an extended educational experience. Besides that, those young people travel to explore art, history and culture. This practice have contributed to the growth of the modern gap year.

The gap year, growing trend of young people take a year off between school and university to explore the world before embarking on formal studies or staring their career [10].It is common in some western countries such as United Kingdom, Australia and United State [11]. Based on Gap Year Association, the top three countries interested in gap year are United Kingdom, Australia and South African.

There are several definitions of 'Gap Year' in the literature. The definitions of gap year are different in term of length of gap year, ex-ante view of gap year and activities during the gap year. Some researchers indicated that gap year is any period of time spend away from the full studies, while some researcher research indicated taking gap year is within three months to one year [10][12][13][14][15]. Besides that, previous research also stated that some taking gap after they graduate high school, some of them indicated that gapper taking gap year after one year enroll in college or university [13]. In term of activities, some researcher stated that gap year which travelling to another country to work or travelling for a break or forced by socioeconomic reason is not considered as taking gap year. However, some studies agree people taking gap year can be any reason. These mixed definitions require the present study to further investigate on gap year.

\section{B. Theory relevant to Gap year}

To date, there are sociological theory indicated that take gap year can increase individual' s economic, social and experiences which are important in education and labor. The previous research more focus on the impact after taking gap year but not what is the reason that lead them to take gap year [5][7][16]. For example, O' Shea 5 indicated that student who took a gap year increased their personal growth and become more maturity to cope with the task assignment by lecturer in school.

One salient theories of behavioral intention and behavior are the theory of planned behavior (TPB). An extension of the theory of reasoned action [17], the theory of planned behaviour is a model that aims to predict and explain human behavior [18]. Central to the theory is the premise that engagement in a particular behaviour is governed by two factors: an individual's intentions and their perceived behavioural control (an individual's confidence in their ability to carry out behaviour). Intentions are a central factor in the theory and its predecessor and summarise an individual's motivation to act, for example, an individual's motivation to study physics in post-compulsory education.
The TPB has received considerable attention in the literature and has met with some degree of success in predicting various behaviors in an expectancy value model of attitude-behavior relationships [19][20][21]. One of the advantages of the TPB model is its ability to identify the determinants of behaviors. There are three predictor variables of the theory of planned behaviour are themselves considered to be underpinned by individuals' beliefs about the behaviour. Attitude is governed by behavioural beliefs (beliefs and evaluations regarding the outcomes of the behaviour), subjective norm by normative beliefs (beliefs about the expectations of others and the motivation to comply with these) and perceived behavioural control by control beliefs (factors that might facilitate or limit the behaviour and the importance of these factors).

\section{Hypothesis and model development}

- Attitude to Intention Path

Attitude plays important role toward behavior. With positive attitude behavior, it will lead desirable consequences while negative attitudes towards behavior will lead to undesirable consequences. Those who participant in gap year believe the break assisted them in decision to undertake further study [11]. Rahim [22] indicated some of students from Malaysia interested to take part in gap-year because they believe the gap-year can gain more work experience apart from just reading from books and learning things during lecture sessions [22]. The favorable belief the gap year will benefit for them will lead to positive consequences of the behavior.

Hypothesis 1: Attitude will have significant relationship with an individual's intention to taking gap year such that the more positive the attitude the more likely the intention.

\section{- Subjective norms to Intention Path}

Theory of planned behavior also indicated predicting that an individual's intention toward an act will be affected by how those most important to the individual perceive the action. A key component of a subjective norm is an individual's motivation to comply with referent in question [23]. The stronger the motivation to comply, the greater influence the subjective norm will have on behavioral intention. Those youth are less likely to take gap year if their parents not support them [11]. It can be proved that subjective norm plays important on taking gap year.

Hypothesis 2: Subjective norms will have a significant relationship with an individual's intention to take gap year such that the more positive the subjective norms the more likely the intention

\section{- Perceived Behavioral Control to Intention Path}

Perceived behavioral control refers to extent which perform a given behavior if they are inclined to do [23]. The concept of perceived behavioral control emphasize on ideas and belief themselves hold about resources to facilitate their successful performance of the behavior. Lyons [24] indicated

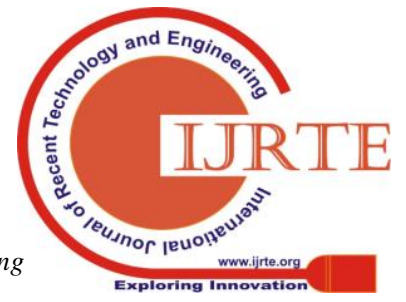


he can't take gap year due to he lacks of direction and can't belief himself can gain anything from take gap year. Greenspon [25] also stated that those who think they don't have financial support or enough financial would not participant in gap year. The previous research showed that an individual's perceived behavioral control of taking gap year will impact their intention to take gap year. Therefore, present study offer the following hypothesis:

Hypothesis 3: Perceived behavioral control will have a significant relationship with an individual's intentions to take gap year such that the higher the perceived control the more likely the intention.

\section{MATERIAL AND METHODS}

\section{A. Sample and Data Collection}

The survey on which the present study is based was developed in and distributed through Google Form. Diploma and undergraduate students from INTI university were solicited through faculty members. The final sample used in this study was 129 . Nearly 300 students were contact resulting in a response rate of $43 \%$. The instrument used in this study consisted of three main parts that were each adopted from previously validated instruments.

The sample consisted of $58(45 \%)$ males and $71(55 \%)$ females. The mean age of the sample is 20.9. The samples are categorized from 84 diploma and 45 from undergraduate students.

\section{B. Measurement}

The questionnaire about attitude is modified based on Cheng and Chu [26]. In this study, attitude toward taking gap year was directly assessed by asking respondents to evaluate four items using a 5-point semantic- differential scale, anchored by 1 , which indicated strongly disagree, and 5, which indicated strongly agree. Two items assessed the instrumental component, and two items measured the experiential component. The Cronbach's for this construct was .86.

In this study, subjective norms were assessed by asking respondents to rate three items addressing whether salient social referents favored taking gap year; respondents answered on a 5-point scale on which 1 indicated strongly disagree and 5 indicated strongly agree. The Cronbach's was .82 .

According to Ajzen's theory [18], perceived behavioral control (PBC) can be assessed by asking respondents about the difficulty of taking gap year. For this study, the measure included three items rated on a 5-point scale on which 1 indicated strongly disagree and 5 indicated strongly agree. The Cronbach's a was .77.

Following Ajzen's study [18], behavioral intentions measurement consisted of two items rated on a 5-point scale on which 1 indicated strongly disagree and 5 indicated strongly agree. The Cronbach's was .83.

\section{Data analysis}

All the responses and measurements were captured and subsequently, the data were coded and then analysed to ensure anonymity and confidentiality of respondents. The quantitative data were analysed using SPSS version 23. The findings were then discussed in line with the objectives of the study, which were to investigate level of awareness of generation $\mathrm{Z}$ on gap year and perception of generation $\mathrm{Z}$ toward gap year.

\section{FINDINGS}

Based on the findings represented in Figure 1, it was noted that most of the respondents $76 \%$ of the respondents stated they are never heard the gap year before and only $24 \%$ of them heard the gap year.

In order to identify if a relationship existed between the variables, a Pearson correlation test was carried out. Table 1 shows the findings. The test indicated evidence that a positive relationship existed between attitude, subjective norms, perceived behavioral control and intention to take gap year.

Multiple regression analysis was used to test the factors that lead to intention to take gap year. The results of the regression on Table 2 indicated the three predictors explained $73.4 \%$ of the variance $(\mathrm{R} 2=.73, \mathrm{~F}(3,125)=48.72, \mathrm{p}<.01)$. It was found that subjective norm significantly predicted intention to take gap year $(\beta=.47, \mathrm{p}<.001)$, as did perceived behavioral control $(\beta=0.50, p<.01)$. But the attitude non significantly predicted intention to take gap year.

\section{Have you ever heard about "Gap year" before?}

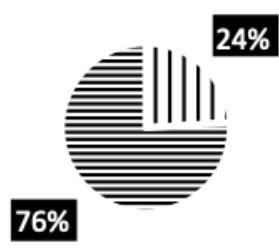

$$
\text { , Yes = No }
$$

Fig. 1. Awareness on Gap Year.

Table 1: Correlation between factors that lead to intention

\begin{tabular}{|l|c|c|c|c|}
\hline & Attitude & $\begin{array}{c}\text { Subjective } \\
\text { Norms }\end{array}$ & PBC & Intention \\
\hline Attitude & 1 & & & \\
\hline $\begin{array}{l}\text { Subjective } \\
\text { Norms }\end{array}$ & $.65(* *)$ & 1 & & \\
\hline PBC & $.74(* *)$ & $.68(* *)$ & 1 & \\
\hline Intention & $.55(* *)$ & $.67(* *)$ & $.67(* *)$ & 1 \\
\hline
\end{tabular}

** Correlation is significant at the 0.01 level (2-tailed). 
Table 2: Multiple regression analyses for variables predicting intention to take gap year. $(\mathrm{N}=129)$

\begin{tabular}{|c|c|c|c|}
\hline Variables & B & Se B & $\beta$ \\
\hline Attitude & -.00 & .12 & .00 \\
\hline Subjective Norms & $.47 * *$ & .10 & .40 \\
\hline $\begin{array}{l}\text { Perceived } \\
\text { Behavioral } \\
\text { Control }\end{array}$ & $.50 * *$ & .12 & .40 \\
\hline $\mathrm{R}^{2}$ & \multirow{2}{*}{\multicolumn{3}{|c|}{$\begin{array}{c}.73 \\
48.72 * *\end{array}$}} \\
\hline $\mathrm{F}$ & & & \\
\hline
\end{tabular}

\section{DISCUSSION}

The present study looked into the gap year decision making of individual utilizing the TPB as a theoretical foundation. From the findings, present study can be concluded the awareness of gap year is growing especially in western countries but not in Malaysia. Students are not aware the concept of gap year even Higher Education Minister has announced the gap year programme in 2017. After two years, still only limited student know about the gap year. This show that Higher education ministry understand the important of gap year but not promote the gap year effectively.

It is interesting to note that attitude did not have an influence on intention to take gap year. Student with a positive attitude toward gap year does not have an intention to participant in gap year. The findings is not aligned with theory of planned behavior [23]. Besides that, Rahim [22] indicated only student interested to take part in gap-year program. Compare to other antecedent of taking gap year intention in this model (perceived behavioral control and subjective norm), this phenomenon can see that good attitude to gap year is not the main concern for the young people to take gap year. Based on Abdullah [27], several issues might inhibit young people to take gap year such as parent influence, timing and the gap year activities. Young people evaluated taking gap year based on sources that they have and their parents. Based on Abdullah [27], parents play important role in young people' decision-making processes.

The findings that indicated perceived behavioral control have a significant relationship with an individual's intentions to take gap year is aligned with theory of planned behavior [23]. This findings also aligned with previous research [24] [25]. Previous research indicated that if they are high self-efficacy and strong belief that they have enough resource, they will intent to take gap year. It proved that getting adequate resources such as money, time and others supporting resources are important factor toward taking gap year.

This study also supported that social norm has an influences on intention taking gap year[23] [11]. This result gives an understanding that social group favor becomes personal favor in that group. Family members, friends and colleagues influences taking gap year. This findings clearly stated that parents are likely to have considerable interest in their children's futures, or may be investing in this future financially.

\section{CONCLUSION}

The findings provide insight for practical implications. Based on the findings, present study found that low awareness towards gap year among Generation Z. It suggest higher education minister or government should provide give more effort to increase the awareness and lets generation $\mathrm{Z}$ understand the benefit of gap year. In additional, awareness not only be given to the young people as well as their parent. From the findings, researcher realize that social factor also play important factor to enhance the intention. Moreover, most of the young people especially Generation $\mathrm{Z}$ still rely on their parents' financial assistance. Therefore, government should put more effort to promote the gap year to young people, parents and employers in Malaysia.

The sampling pool was limited to only those students in INTI university. It is recommended that future researchers conduct a similar study with a Malaysia representative sampling frame to obtain more comprehensive data. Although the quantitative approach allowed examination of the influence of key factors on intention to take gap year, it was unable to fully provide the underlying reasons to the phenomenon. In this regard, a qualitative research approach is useful for exploring more detailed reasons underlying the relationships among variables and taking gap year through different characteristics.

\section{REFERENCES}

1. Infographics - Principal Statistics of Labour Force, Malaysia 2016 Department of Statistics: Malaysia; 2017 April 08

2. Key Statistics of Labour Force in Malaysia, June 2019. Department of Statistics: Malaysia; 2019 August 09

3. Aziz,Hazlina. Graduate skills gap [Internet]. Kuala Lumpur: New Straits Times; 2018 [October 3]. Available from https://www.nst.com.my/education/2018/10/417327/graduate-skills-ga $\mathrm{p}$

4. Stehlik T. Mind the gap: School leaver aspirations and delayed pathways to further and higher education. Journal of Education and Work. 2010 Sep 1;23(4):363-76

5. O'shea J. Delaying the academy: A gap year education. Teaching in Higher Education. 2011 Oct 1;16(5):565-77.

6. Lyons K, Hanley J, Wearing S, Neil J. Gap year volunteer tourism: Myths of global citizenship?. Annals of tourism research. 2012 Jan 1;39(1):361-78.

7. Nieman MM. South African students' perceptions of the role of a gap year in preparing them for higher education. Africa Education Review. 2013 Feb 1;10(1):132-47.

8. Walsh, B.. Closing the Gap Year Gap [Internet]. UK: GSE; 2016. Available https://www.gse.harvard.edu/news/uk/16/05/closing-gap-year-gap

9. White KM, O'Connor EL, Hamilton K. In-group and role identity influences on the initiation and maintenance of students' voluntary attendance at peer study sessions for statistics. British Journal of Educational Psychology. 2011 Jun;81(2):325-43.

10. Coetzee M, Bester S. The possible value of a gap year: A case study. South African Journal of Higher Education. 2009 Jan 1;23(3):608-23.

11. Hango, Darcy. Length of Time between High School Graduation and Enrolling in Postsecondary Education: Who Delays and Who Does Not? Canada: Culture Tourism and the Centre for Education Statistics; 2011 May 25. Report No.:90.

12. Ferrer AM, Menendez A. The puzzling effects of delaying schooling on Canadian wages. Canadian Public Policy. 2014 Sep;40(3):197-208.

13. Hango D. Taking time off between high school and postsecondary education: Determinants and early labour market outcomes. Statistics Canada, Culture, Tourism and the Centre for Education Statistics; 2008 
14. Lovestrand, Amy. Taking a Gap Year before Starting Post-Secondary Education: Why It Benefits Some and Hurts Others [dissertation]. Newfoundland: University of Newfoundland; 2015; Available from https://shoulditakeagapyear.files.wordpress.com/2015/03/taking-a-gapyear.pdf

15. Lumsden, Marilyn and John Stanwick. Who Takes a Gap Year and Why?. Australia: Longitudinal Surveys of Australian Youth; 2012. Briefing Paper 28. Available from: http://files.eric.ed.gov/fulltext/ED533076.pdf.

16. Martin AJ. Should students have a gap year? Motivation and performance factors relevant to time out after completing school. Journal of Educational Psychology. 2010 Aug;102(3):561.

17. Azjen I. Understanding attitudes and predicting social behavior Englewood Cliffs. 1980.

18. Ajzen I. The theory of planned behavior. Organizational behavior and human decision processes. 1991 Dec 1;50(2):179-211.

19. Ajzen. The directive influence of attitudes on behavior. In: P. Gollwitzer \& J. A. Bargh, editors. Psychology of Action. New York: Guilford; 1996. p. [385-403].

20. Cheng S, Lam T, Hsu CH. Testing the sufficiency of the theory of planned behavior: a case of customer dissatisfaction responses in restaurants. International Journal of Hospitality Management. 2005 Dec 1;24(4):475-92.

21. Tolma EL, Reininger BM, Evans A, Ureda J. Examining the theory of planned behavior and the construct of self-efficacy to predict mammography intention. Health education \& behavior. 2006 Apr;33(2):233-51.

22. Rahim, S. Gap year option: Varsity students to get a year off from study Kuala Lumpur: New Straits Times; 2017 [January 13]. Available from https://www.nst.com.my/news/2017/01/203878/gap-year-option-varsit y-students-get-year-study.

23. Ajzen, I. The theory of planned behavior. In: P. A. M. Lange, A. W. Kruglanski, \& E. T. Higgins,editors. Handbook of theories of social psychology. London, UK: Sage; 1996. Vol. 1, pp. [438-459].

24. Lyons . Why I Didn't Take A Gap Year, And Why That's Okay [Internet]. Austin: Study Break; 2017 [February 14 ]. Available from: https://studybreaks.com/college/gap-year/

25. Greenspon,J. The Gap Year: An Overview of the Issues. Ontario: Centre for the Study of Living Standards; 2017. CSLS Research Report 2017-01

26. Cheng PY, Chu MC. Behavioral factors affecting students' intentions to enroll in business ethics courses: A comparison of the theory of planned behavior and social cognitive theory using self-identity as a moderator. Journal of Business Ethics. 2014 Sep 1;124(1):35-46.

27. Abdullah D. Making the Gap Year a Reality: Six Issues for Consideration. IHE [Internet]. 2017Apr.15 [cited 2019Aug.15];0(89):13-4. Available from: https://ejournals.bc.edu/index.php/ihe/article/view/9837

\section{AUTHORS PROFILE}

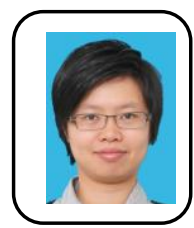

Dr. Yip Foon Yee is a passionate researcher and has been actively involved in numerous research projects since 2016. Her area of expertise includes human resource management, consumer behavior, organizational behavior, learning and psychology. She is lead researcher in internal grant and actively involved in many national and international conferences. Recently, her research focus on perception and behavior of young generation. 